\title{
AnÁlise da EFETIVAÇÃo do ACORdo InTERnacional da Previdência Social entre o INSS e o INPS de Brasil-Itália
}

\author{
ANALYSIS OF THE ENFORCEMENT OF THE INTERNATIONAL \\ AGREEMENT ON SOCIAL SECURITY BETWEEN BRAZIL AND ITALY
}

Maria José Jung Gonzalez;

\section{RESUMO}

O presente trabalho trata do acordo internacional da previdência social entre os países Brasil e Itália e a importância do conhecimento deste acordo, uma vez que é pouco divulgado. Inicialmente, aborda-se o cenário da saúde internacional, com um histórico dos sistemas de saúde brasileiro e italiano, o acordo existente entre os países e a análise de sua efetivação pelo método de conveniência. A tendência dos acordos internacionais é pela globalização em porte mundial, incrementando e ratificando a necessidade de se romper barreiras jurídicas e políticas, envolvendo um grande esforço no tratamento migratório. O principal objetivo deste acordo internacional é garantir a seguridade social prevista na legislação dos dois países, inclusive com o intuito de criar uma base legal comum quanto às obrigações e aos direitos previdenciários. O sistema de benefícios previdenciários é hoje percebido como ferramenta de segurança e bem-estar indispensável para atender às necessidades de estabilidade dos trabalhadores migrantes, e neste trilho, tornase obrigatória sua divulgação.

\section{Palavras-chave:}

Previdência Social; Acordo Internacional; Brasil; Itália.

(*) Bacharel em Comunicação Social - Jornalismo, Universidade do Vale do Rio dos Sinos (Unisinos); especialista em Direito Sanitário, Unisinos e Escola de Saúde Pública do Rio Grande do Sul e especialista em Relações Internacionais e Diplomacia, Unisinos. Membro de Comissão da Advogados sem Fronteiras Brasil. Porto Alegre/RS - Brasil. E-mail: <zecajung@ terra.com.br>. Recebido em 15.07.10. Revisado em 18.12.10. Aprovado em 30.01.11. 


\section{ABSTRACT:}

The present paper approaches the international social security agreement between Brazil and Italy and the importance of this agreement, once it is not well known. Initially, it approaches the international health scene, with a historic of Brazilian and Italian health systems; the agreement exists between the countries and the analysis of the execution by the convenience method. The tendency of the International agreements is the worldwide globalization, ratifying the need of breaking juridical and political obstacles involving a great effort in the migratory treatment. The main goal of this international agreement is to guarantee the social welfare planned in the legislation of the two countries, including intending to create a common legal base regarding the obligations and rights of the beneficiary. Nowadays the benefit system is seen as a security tool and indispensable welfare to meet the needs of stability of the migrant workers, and in this trail, it becomes mandatory its divulgation.

\section{Keywords:}

Social Security, International Agreement; Brazil; Italy.

\section{INTRODUÇÃO}

A saúde é um problema global, e com a globalização, a saúde é um bem que deve ser trabalhado de modo programado e explícito. A saúde global é uma finalidade social desejável e de evidência prioritária. Conforme artigo publicado por Dias e Gonçalves ${ }^{(1)}$ :

A migração internacional é considerada um dos maiores desafios da Saúde Pública a nível mundial. Atualmente há uma reconhecida necessidade de compreensão da movimentação da população e do seu impacto na saúde, quer para os países de acolhimento, trânsito e origem, quer para as populações, migrantes e autóctones. Neste contexto, é fundamental um melhor conhecimento dos determinantes de saúde e do estado de saúde dos indivíduos e comunidades imigrantes. A crescente imigração, a que muitos países estão sujeitos, torna necessário refletir sobre políticas e estratégias de saúde integradoras e sustentadas, que produzam efeitos reais na redução de riscos e vulnerabilidades e permitam obter ganhos efetivos em saúde.

(1) DIAS, Sônia; GONÇALVES, Aldina. Migração e saúde. Revista Imigração. número temático Imigração e saúde, Lisboa, n. 1, set. 2007. Disponível em: <www.oi.acidi.gov.pt/docs/Revista_1/ migracoes1_art1.pdf>. Acesso em: 09 mar. 2010. 
As políticas de imigração vigentes nos países de acolhimento que não promovem a integração social e contribuem para a manutenção das condições associadas à vulnerabilidade das populações imigrantes podem influenciar de forma negativa a sua saúde. Apesar da existência de cobertura e acesso universal aos cuidados de saúde na maior parte dos países receptores de imigrantes, o que se constata é que muitas vezes as comunidades não se beneficiam de todos os serviços disponíveis e não são efetivamente abrangidas pelos sistemas existentes de promoção da saúde, prevenção ou tratamento da doença. Os acordos internacionais são as mais importantes fontes de direito internacional e sua relevância está, principalmente, na garantia oferecida pelo direito escrito, ou seja, normatizado.

Portanto, os acordos internacionais que tratam sobre Previdência Social são uma forma de proteger os direitos dos trabalhadores envolvidos em movimentos migratórios, tendo-se em vista a globalização e o trânsito de pessoas que ela gera. Assim um Estado soberano deve garantir os direitos de seus cidadãos, mesmo quando esses estiverem fora de sua área territorial. O Brasil possui acordos internacionais bilaterais de previdência social com diversos países: Cabo Verde, Itália, Grécia, Espanha, Chile, Portugal e Luxemburgo, ultimando formalizar com o Canadá, Estados Unidos, Japão, Alemanha e Bélgica; e acordo internacional multilateral com os países do MERCOSUL (Argentina, Uruguai e Paraguai).

Nessa pesquisa, optou-se pela relação Brasil-Itália, pois se estima que haja cerca de 30 milhões de ítalo-brasileiros, descendentes de imigrantes italianos que chegaram ao Brasil entre 1870 e 1960. A comunidade de descendentes de italianos no Brasil é considerada a maior do mundo, com $16 \%$ de ítalo-descendentes. A maioria dos ítalo-brasileiros que hoje vivem no país mantêm a maior parte dos costumes tradicionais italianos. A contribuição dos italianos é notável em todos os setores da sociedade brasileira, principalmente nas mudanças sociais e econômicas realizadas no campo e nas cidades onde se estabeleceram. Pode-se citar desde o modo de vida, influenciado pelo catolicismo, bem como as artes, música, arquitetura, alimentação e o empreender italiano na abertura e desenvolvimento de empresas e trabalhos especializados. No campo, foi notável a introdução de novas técnicas agrícolas e, principalmente, a promoção da mudança estrutural dos latifúndios para pequenas propriedades agrícolas, bem como a introdução da policultura de produtos.

Frente a esta miscigenação arraigada dos dois povos, vê-se a necessidade de avaliar a efetivação dos direitos garantidos aos brasileiros e italianos pelo acordo do INSS e INPS entre os dois países. Quais os principais problemas encontrados no cumprimento deste acordo? Existem informações deste acordo disponíveis aos brasileiros e italianos? O objetivo do trabalho é analisar a efetivação do direito aos brasileiros e italianos quanto ao acordo do INSS e o INPS entre Brasil-Itália. Os objetivos específicos são o de informar 
a necessidade do tema saúde nos movimentos migratórios, informar e promover o fortalecimento do acordo e questionar a sua validação.

Desenvolveu-se um levantamento de dados por meio da aplicação de questionários sobre as informações dos usuários brasileiros e italianos quanto ao conhecimento do acordo internacional e a sua utilização. A partir de um referencial teórico sobre o cenário da saúde internacional, e do sistema de saúde brasileiro e italiano, com a metodologia exploratória das questões temáticas, optou-se por um método de pesquisa por conveniência.

A escolha do tema justifica-se pelo grande vínculo existente entre Brasil e Itália, com o Estado do Rio Grande do Sul sendo densamente colonizado por imigrantes italianos. Considerando que este vínculo se traduziu de forma transdisciplinar, envolvendo os aspectos culturais, de costumes, legislativos, de transferências de tecnologia, enfim, toda a gama de irmandade entre os povos de todas as regiões italianas e seus descendentes brasileiros em diversos graus de gerações é importante, na crescente globalização, que se estabeleçam os princípios de cooperação entre os dois países, quando o fluxo de migração continua intenso unindo os hemisférios norte e sul.

\section{DESENVOL VIMENTO}

O artigo trata da importância do tema direito à saúde no cenário internacional com relação ao acordo internacional da Previdência Social do Brasil-Itália e a análise de sua efetivação.

\subsection{Direito à saúde no cenário internacional}

A proteção ao direito à saúde e sua consequente legitimação consagram-se como pressupostos para o pleno desenvolvimento de cada pessoa, enquanto membro ativo de uma sociedade democrática e igualitária. Entretanto, para a concretude de tais pressupostos, exige-se não somente a garantia do acesso universal ao direito à saúde, mas também o seu efetivo cumprimento e satisfação, transcendendo desta maneira a esfera nacional e abarcando, assim, questões de âmbito internacional que circundam a saúde e seu reconhecimento como um direito fundamental ao homem.

O direito à saúde no Brasil, como aponta a nossa Constituição Federal de 1988, é um direito de todos e um dever do Estado, calcado no art. 196 da Carta Magna e garantido mediante políticas sociais e econômicas que visam à redução do risco de doença e de outros agravos e ao acesso universal e igualitário às ações e serviços para sua promoção, proteção e recuperação. Por meio deste dispositivo legal, o termo saúde se constitui como um direito reconhecido igualmente a toda a população, além de ser um meio de preservação e de qualidade de vida, sendo este o bem máximo da humanidade. 
Já na Itália, o direito à saúde, por intermédio da Constituição da República Italiana de 1948, se constitui como direito fundamental do homem, sendo elevado ao status de um dos direitos de solidariedade inviolável, consagrado no art. 32 da Constituição. Por conseguinte, trata-se de um direito absoluto, ao qual corresponde o dever de promover e garantir o bem-estar de cada indivíduo, enquanto membro do Estado Social. Hoje, na sociedade contemporânea, a saúde é indiscutivelmente um fundamental direito humano, além de ser também um importante investimento social. Na medida em que os governos têm o objetivo de melhorar as condições de saúde de todos os cidadãos, é necessário que invistam recursos em políticas públicas de saúde, capazes de garantir programas efetivos para a sua promoção. Todavia, garantir o acesso igualitário a condições de vida saudável e satisfatória a cada ser humano constitui um princípio fundamental de justiça social e, portanto, exige também uma produtividade complexa por parte da sociedade e do Estado, sendo necessária a intensificação dos esforços para coordenar as intervenções econômicas, sociais e sanitárias mediante uma ação integrada.

Através dos tempos ocorreu a evolução da humanidade e a chegada da civilização, juntando-se a este processo também a evolução da saúde. Inicialmente, essa foi pensada como uma forma de exterminar todos os males que acometiam e ameaçavam a espécie. Segundo Scliar ${ }^{(2)}$ :

É perfeitamente compreensível que a humanidade tenha primeiro pensado a saúde como uma forma de eliminação dos males que afligiam os componentes da espécie. Ao longo do tempo os seres humanos foram invariavelmente acometidos por doenças que ameaçaram a sua sobrevivência. Nos tempos bíblicos, os surtos de lepra, peste e cólera eram a grande preocupação da civilização. Na Índia e na China antigas, foi a varíola. Na antiguidade Grego-Romana, a malária se fez presente. Na Idade Média, ocorreu a "Peste Negra", onda de peste bubônica que assolou a Europa [...]

Seguindo, conforme o mesmo autor:

a saúde e suas acepções perpassam a história da civilização humana, sendo que o primeiro conceito de saúde, ao que tudo indica, pode ser atribuído aos gregos de Esparta, onde o axioma Mens Sana in Corpore Sano nada mais é que o ponto culminante da definição do que é ter saúde. Para eles, na verdade, o ser humano ideal era uma criatura equilibrada no corpo e na mente e de proporções definitivamente harmoniosas.

Segundo Sturza ${ }^{(3)}$ :

Neste eixo destacamos Hipócrates, que iniciou-se na saúde através da medicina, desencadeando uma tradição médica que procurou fazer

(2) SCLIAR, Moacir. Do mágico ao social: a trajetória da saúde pública. Porto Alegre: L \& PM, 1987. (3) STURZA, Janaína Machado. O direito à saúde na sociedade contemporânea: a figura jurídica do dano biológico na Itália e a proteção à saúde no Brasil. Disponível em: <www.unisc.br/cursos/ pos_graduacao/.../janaina_machado_sturza.pdf>. Acesso em: 10 mar. 2010. 
com objetividade o registro dos sintomas, libertando-se das práticas mágicas da medicina egípcia e babilônica, deixando-nos até hoje o legado do Juramento de Hipócrates, firmado em todo o mundo pelos profissionais da medicina.

Com a chegada da Idade Média, as atividades científicas tiveram um declínio, e atingiram também a área da saúde. Notoriamente, foi também a própria igreja que retomou as ideias gregas, iniciando um processo de resgate da medicina de Hipócrates. Desde então, as acepções de saúde passaram a se expandir pelos processos de evolução da medicina e, em 1543, foi publicado o primeiro livro ilustrado sobre anatomia, baseado, fundamentalmente, nas experiências de dissecação de cadáveres desenvolvidas nos mosteiros.

Já no século XVII as sociedades europeias presenciaram rebeliões e perseguições religiosas, testemunhando também o avanço do racionalismo, que resultou em novas descobertas científicas, bem como no desenvolvimento de alguns dos conhecimentos científicos que atingiram momentos grandiosos com pesquisadores como Descartes, que percebeu ser a saúde a ausência de doença ${ }^{(4)}$.

Assim, a industrialização do século XIX trouxe consigo a urbanização, acarretando ao Estado a obrigação de assumir a responsabilidade pela saúde da população. Nesse mesmo período, a preocupação com as questões sanitárias ganhou força e, em 1851, doze países assinaram a Primeira Conferência Internacional Sanitária, elaborada com o intuito de combater as epidemias de cólera, peste e febre amarela que acometiam os trabalhadores. Já o ano de 1864 foi marcado pela criação da Cruz Vermelha Internacional, significando uma grande conquista para a saúde ${ }^{(5)}$.

A chegada do século XX impulsionou marcantes transformações sociais, juntamente com as grandes guerras ocorridas no mesmo período. Até então a saúde era vista como algo individual, e no século XXI, auge da expansão dos meios de comunicação, o constante crescimento da produção proporcionou a maior obtenção de condições de bem-estar e de acesso a serviços, refletindo-se nos setores da saúde. Com isso, após vários períodos da história, surgiram os aparatos legais internacionais, nos quais o direito à saúde tornou-se um direito adquirido a todo o povo, ao acesso universal e igualitário.

O direito à saúde é reconhecido nas Constituições Brasileira e Italiana, e também nos tratados e nas declarações de direito internacional. A Convenção de Viena é o tratado internacional que disciplina a questão da

(4) DALLARI, Sueli Gandolfi. O direito à saúde. Revista de Saúde Pública. São Paulo, n. 22, p. 5763, 1988.

(5) ROCHA, Julio César de Sá da. Direito da saúde: direito sanitário na perspectiva dos interesses difusos e coletivos. São Paulo: LTr, 1999. 
integração entre o ordenamento jurídico internacional e o nacional. Em âmbito internacional, cabe destaque, ainda, à Declaração Universal dos Direitos do Homem $^{(6)}$, também chamada de Declaração Universal da ONU, de 1948, pioneira no que diz respeito à previsão expressa do direito à saúde, destacando-se o art. 25:

Toda a pessoa tem direito a um nível de vida suficiente para lhe assegurar e a sua família a saúde e o bem-estar, principalmente quanto à alimentação, ao vestuário, ao alojamento, a assistência médica e ainda quanto aos serviços sociais necessários; e tem direito a segurança no desemprego, na doença, na invalidez, na viuvez, na velhice ou noutros casos de perda de meios de subsistência por circunstâncias independentes da sua vontade.

No cenário internacional, acresce-se o Tratado de Roma, assinado em 25 de março de 1957, vigorando a partir do dia 1o de janeiro de 1958. Esse Tratado foi assinado na cidade de Roma e instituiu a Comunidade Europeia, mencionando em vários de seus artigos, o aspecto saúde: como proteção e preservação da vida das pessoas e saúde do trabalhador. Em 12 de setembro de 1978, foi ratificada a Declaração de Alma-Ata (ex-URSS) ${ }^{(7)}$, quando então foi realizada a Conferência Internacional sobre os Cuidados Primários de Saúde, que dispõe sobre a necessidade de ação de todos os governos, de todos os que trabalham no campo da saúde, e do desenvolvimento de uma ação de todas as comunidades para promover a saúde de todos os povos do mundo.

\subsection{Sistemas de saúde brasileiro e italiano}

Após a Segunda Guerra Mundial, em dezembro de 1947, promulgouse a Constituição Italiana(8) que, começou a vigorar em $1^{\circ}$ de janeiro de 1948. No seu artigo 32 refere: "A República tutela a saúde como direito fundamental do indivíduo e interesse da coletividade, e garante tratamento gratuito aos indigentes [...]". A Itália, na década de 1960, estava imersa em grandes dificuldades e, além disso, a evolução do perfil demográfico da população, o incremento das necessidades de saúde e o endividamento do mutualismo fortemente fragmentado em inúmeras operadoras de planos e seguros exigiram um (re)pensar o sistema ${ }^{(9)}$. No

(6) DECLARAÇÃO UNIVERSAL DOS DIREITOS DO HOMEM (1948). Disponível em: <http:// www.ghente.org/doc_juridicos/decdirhumanos.htm>. Acesso em: fev. 2010.

(7) DECLARAÇÃO DE ALMA-ATA — URSS (1978). Disponível em: <http://www.opas.org.br/coletiva/ carta.cfm?idcarta>. Acesso em: fev. 2010.

(8) REPUBBLICA ITALIANA. La Costituzione della Repubblica Italiana. Roma, 1947. Disponível em: <http://www.quirinale.it/costituzione/costituzione.htm>. Acesso em: 25 fev. 2010.

(9) CAVICCHI, I. La sanitá. Bari: Dédalo, 2005. 
período compreendido entre os anos 1960 e o final do século XX, a Itália viveu, no campo da saúde, inúmeras reformas.

Segundo Berlinguer, Teixeira e Campos(10), essa Reforma ocasionou uma complexa crise hospitalar e, dez anos após, em dezembro de 1978, eclodiu uma ampla mobilização social por uma reforma sanitária, com a participação de milhares de pessoas da sociedade civil, principalmente trabalhadores, como resultado de um processo de lutas ideológicas e políticas.

Ainda conforme os autores, a Reforma Sanitária resultou na criação do "Serviço Sanitário Nacional" - SSN, regulamentado por meio da Lei n. 833/ 78, comprometido com uma moderna consciência sanitária, com base em um ideário democrático social, com uma proposta de universalizar o acesso e descentralizar a atenção à saúde, representando, assim, um avanço para os setores mais frágeis da sociedade italiana. O lema era direito, saúde e garantia de assistência a todos e os princípios doutrinários eram: a globalidade, a igualdade, a universalidade e a unicidade. O país conseguiu finalmente romper com o mutualismo e instituir um sistema de saúde que se mostrou comprometido com a cidadania plena como direito universal, e, deste modo, com o direito universal à saúde.

O país entrou nos anos 90 carregado de instabilidade político-econômica e de insatisfação em diversos setores da sociedade civil. Esse contexto, somado às inúmeras dificuldades para conter a despesa sanitária, determinou, na leitura do Estado, uma necessidade pontual de buscar soluções urgentes de adequação. Fundou-se, em 1992, por meio da Reforma De Lorenzo Garavaglia um novo modelo de gestão sanitária - corporação - como fruto da percepção estatal de que a garantia do direito universal à saúde estaria na dependência dessa adequação. A partir desse modelo, o sistema privado tornara-se um grande parceiro do Estado. Essa reforma correspondeu à regionalização do sistema e nesse novo cenário gerencial nasceu um novo sujeito: a tecnocracia, representada pelos seus diretores gerais e colegiados ${ }^{(11)}$.

No Brasil, a primeira forma de proteção social surgiu por meio da organização de categorias de trabalhadores no formato de associações de auxílio mútuo em regime privado e facultativo destinado à resolução de problemas referentes à invalidez, doença e morte ${ }^{(12)}$. O primeiro montepio surgiu na fase de império, em 1835, e funcionou mediante o mutualismo e denominava-se Montepio Geral dos Servidores do Estado(13).

(10) BERLINGUER, G.; TEIXEIRA, S. F.; CAMPOS, G. W. S. Reforma sanitária Itália e Brasil. São Paulo: Hucitec, 1988.

(11) CAVICCHI, I. op. cit.

(12) LIMA, N. T.; FONSECA, C. M.; HOCHMAN, G. A saúde na construção do estado Nacional no Brasil: reforma sanitária em perspectiva histórica. In: LIMA, N. T. et al. (Orgs.). Saúde e democracia: história e perspectivas do SUS. Rio de Janeiro: Fiocruz, 2005.

(13) GENTIL, D. L. Breve relato histórico do sistema de proteção social. In: A política fiscal e a falsa crise da seguridade social brasileira: análise financeira do período 1990-2005. 2006. Tese (Doutorado em Economia) — Instituto de Economia da UFRR, Rio de Janeiro, 2006. 
Em um cenário político de grandes transformações sociais e econômicas para a inclusão do modo de produção capitalista, o governo da Primeira República, na emergência do século $X X$, voltou-se para a construção das primeiras políticas públicas de saúde, dentre elas a reforma sanitária, necessária para vencer as epidemias e preservar a política de exportação do café, carro-chefe da economia nacional ${ }^{(14)}$.

Em 1923, foram instituídas as Caixas de Aposentadorias e Pensões (CAPs), com a função de ofertar pensões, aposentadorias, pecúlios e assistência médica aos marítimos, ferroviários e seus dependentes. As CAPs eram organizações de direito privado voltadas a grupos específicos de servidores públicos e estruturadas com base em princípios de seguro social, modelo que vinculava os benefícios prestados às contribuições dos segurados $^{(15)}$.

Posteriormente, em 1933, o governo Vargas criou os Institutos de Aposentadorias e Pensões (IAPs) — autarquias vinculadas ao Ministério do Trabalho - com contribuições obrigatórias dos empregadores e empregados, destinadas à prestação de benefícios às categorias profissionais de trabalhadores urbanos, como os marítimos, estivadores, servidores públicos federais, industriários e comerciários, sendo excluídos outros trabalhadores, tanto urbanos como rurais. Desse modo, percebeu-se que o direito à saúde ainda permanecia restrito a uma parte da população.

Com o golpe militar no Brasil, em 1964, os interesses de mercado no setor de saúde se fortaleceram e o governo criou, em 1966, o Instituto Nacional de Previdência Social (INPS), consolidando o modelo médico assistencial privatista(16). Em meados dos anos 1970, diante da conjuntura de crise social vivida no Brasil, ganhou impulsão o Movimento Sanitário, formado pela articulação entre intelectuais, acadêmicos e profissionais de saúde insatisfeitos com as iniquidades em saúde vigentes até então. Esse movimento passou a lutar por um Sistema Único de Saúde - universal e equânime - e pela redemocratização do país, concretizados uma década mais $\operatorname{tarde}^{(17)}$.

No ano seguinte, o governo criou o Sistema Nacional de Previdência Social (SINPAS), separando o setor de benefícios da assistência médica, ambos anteriormente sob responsabilidade do INPS, cabendo a este estritamente o controle dos benefícios, enquanto o recém-criado INAMPS ficou responsável pela assistência médica ${ }^{(18)}$.

(14) VERDI, M. I. M. Da Haussmannização às cidades saudáveis: rupturas e continuidades nas políticas de saúde e urbanização na sociedade brasileira do início e do final do Século XX. 2002. Tese (Doutorado em Enfermagem) — Universidade de Santa Catarina, Florianópolis, 2002.

(15) LIMA, N. T.; FONSECA, C. M.; HOCHMAN, G. op. cit..

(16) MENDES, E. V. Uma agenda para a saúde. 2. ed. São Paulo: Hucitec, 1999.

(17) DA ROS, M.A. Uma visão da reforma curricular a partir do movimento sanitário. In: PEREIRA, M. J. L.; COELHO, E. B. S.; DA ROS, M. A. (Orgs.). Da proposta à ação: currículo integrado do Curso de Medicina da UFSC. Florianópolis: Ed. UFSC, 2005.

(18) COHN, A.; ELIAS, P. E. (Orgs.). Saúde no Brasil: políticas e organização de serviços. São Paulo: Cortez; Cedec, 1996. 
A luta histórica do movimento sanitário se refletiu na aprovação do capítulo sobre a saúde na Constituição Federal de 1988 e na criação do Sistema Único de Saúde (SUS), que configurou um fato inédito no país ${ }^{(19)}$. 0 Estado Brasileiro iniciou, por meio do SUS, um processo de construção social com vistas a edificar um novo espaço de construção de saúde.

Analisando a dinâmica da construção histórica do direito à saúde no Brasil e na Itália, observou-se que os sistemas de proteção social, não nasceram em ambas as realidades, como uma ação do Estado provedor. Os caminhos iniciais trilhados para a garantia dessa proteção, ideologicamente semelhantes, foram materializados a partir de ações da classe trabalhadora brasileira e da classe trabalhadora italiana. O Brasil e a Itália iniciaram essa construção com base em modelos societários de socorro mútuo para a garantia da assistência em saúde, exigida pelo capitalismo, novo modelo de organização social inaugurado com a Revolução Inglesa.

Observando a evolução do direito à saúde na Itália e no Brasil notou-se que, em ambos os Estados, a origem da concretização deste direito, fruto da iniciativa dos trabalhadores, pareceu decorrer da necessidade do ser humano em dar respostas imediatas aos problemas que obstaculizam a sua existência e que, deste modo, comprometem sua força de trabalho. Ainda que consideradas as diferenças pontuadas, ambos os países conseguiram viver a tão desejada reforma sanitária, uma necessidade de colocar a saúde como centro de reflexão e ação no sentido de construir sistemas pautados na universalidade. Os dois países conquistaram, no plano jurídico, o status da saúde como um direito universal, como uma condição sine qua non para gozar do direito à vida.

\subsection{Acordo da previdência social entre Brasil-Itália}

Os acordos internacionais inserem-se no contexto da política externa brasileira, conduzida pelo Ministério das Relações Exteriores ${ }^{(20)}$ e resultam de esforços do Ministério da Previdência Social ${ }^{(21)}$ e de entendimentos diplomáticos entre governos. Os motivos pelos quais o Governo brasileiro firmou acordos internacionais com outros países enquadram-se em pelo menos uma das seguintes situações: elevado volume de comércio exterior; recebimento no país de investimentos externos significativos; acolhimento, no passado, de fluxo migratório intenso; relações especiais de amizade.

(19) ESCOREL, S. Reviravolta na saúde: origem e articulação do movimento sanitário. Rio de Janeiro: Fiocruz, 1998.

(20) MINISTÉRIO DAS RELAÇÕES EXTERIORES. Disponível em: <http://www.mre.gov.br>. Acesso em: 23 fev. 2010.

(21) MINISTÉRIO DA PREVIDÊNCIA SOCIAL. Disponível em: <http://www.previdenciasocial.gov.br>. Acesso em: 23 fev. 2010. 
Justamente nesta esteira é que se incluem os acordos internacionais bilaterais, com objetivo particularizado de garantir os direitos de seguridade social aos imigrantes de ambos os países envolvidos, ainda que não decorrentes de modificação da legislação vigente em cada país.

Portanto, os principais tópicos do acordo no que se refere à Previdência Social entre os países Brasil e Itália são:

Acordo de Migração assinado a 9 de dezembro de 1960, em Roma.

Decreto Legislativo n. 101, de 18 de novembro de 1964. Aprova o texto do Acordo.

Decreto n. 57.759, de 8 de fevereiro de 1966, publicado no DOU n. 30, de 11 de junho 1966. Promulga o Acordo.

Acordo Administrativo, assinado em Brasília a 19 de março de 1973, publicado no DOU n. 111 de 12 de junho de 1973.

Protocolo Adicional ao Acordo de Migração, assinado em Brasília a 30 de janeiro de 1974.

Entrada em vigor: 05 de agosto 1977

Registrado no Secretariado da ONU em 8 de maio de 1974 sob $n$. 13284

Ratificado pela Itália a 23 de dezembro de 1974

Acordo assinado a 25 de junho de 1995, em Brasília.

Primeiramente, com o ACORDO DE MIGRAÇÃO entre a República dos Estados Unidos do Brasil e a República Italiana, ficam estabelecidos, a partir do art. 36, os direitos concernentes à legislação previdenciária.

Com o DECRETO LEGISLATIVO N. 101, de 1964, é aprovado o Acordo de Migração entre a República dos Estados Unidos do Brasil e a República Italiana, assinado em Roma, em 9 de dezembro de 1960.

Assim, o DECRETO N. 57.759, de 8 de fevereiro de 1966, promulga o Acordo de Migração com a Itália. O Presidente da República, havendo o Congresso Nacional aprovado pelo Decreto Legislativo n. 101, de 1964, o Acordo de Migração assinado entre os Estados Unidos do Brasil e a República Italiana, em Roma, em 9 de dezembro de 1960; e havendo o referido Acordo entrado em vigor, de conformidade com seu artigo 51, em 26 de fevereiro de 1965, data em que se efetuou no Rio de Janeiro, a troca dos instrumentos de ratificação, decreta que o mesmo apenso por cópia ao presente Decreto, seja executado e cumprido tão inteiramente como nele se contém.

O ACORDO ADMINISTRATIVO referente à aplicação dos artigos $37 \mathrm{e}$ 43 do acordo de migração entre a República Federativa do Brasil e a República Italiana, de 9 de dezembro de 1960. 
Por fim, o PROTOCOLO ADICIONAL AO ACORDO DE MIGRAÇÃO, assinado em Brasília, em 30 de janeiro de 1974, em quatro exemplares originais, dois em língua portuguesa e dois em idioma italiano, e cujos textos fazem igualmente fé. Tratam das normas de acidentes de trabalho, Previdência Social, seguros e as transferências de trabalhadores brasileiros e italianos para o Estado contratante que o acolheu.

Estabelecidos os ditames acordados, na cronologia e prioridade enfocadas, aborda-se os questionamentos quanto ao seu conhecimento e sua utilização por parte dos potenciais beneficiários.

\subsection{Análise da efetivação do acordo}

O artigo tem a proposta de levar o conhecimento do acordo internacional de Brasil-Itália, e entre os países de uma forma geral, com sucesso no alcance dos objetivos a que se proponham. Questões de limites territoriais, meramente burocráticas, estão sendo absorvidas pelo tempo e hoje, através da globalização, têm-se, em sua plenitude, direitos e garantias expressos de forma bilateral e multilateral em tratados formais, dando equiparação de tratamento ao sujeito do trabalho realizado entre dois ou mais países. Esses acordos vêm a equiparar os trabalhadores estrangeiros aos trabalhadores nacionais, dando solução a problemas social-trabalhistas, proporcionando mais dignidade aos trabalhadores migrantes.

O principal objetivo do acordo internacional é garantir o direito à seguridade social previsto na legislação dos dois países, com o intuito de criar uma base legal comum quanto às obrigações e aos direitos previdenciários. $\mathrm{A}$ tendência dos acordos internacionais é pela globalização em porte mundial, incrementando e ratificando a necessidade de se romperem barreiras jurídicas e políticas, envolvendo um grande esforço no tratamento migratório.

O levantamento de dados a respeito do Acordo da Previdência entre Brasil e Itália, por meio de questionários, envolveu duas amostras: uma dirigida a dez brasileiros e outra a dez italianos, todos com uma permanência mínima de 6 meses nos seus países de destino. Tal coleta de dados ocorreu por e-mail com perguntas objetivas, obtendo-se uma avaliação do conteúdo com a organização do material e com análise qualitativa dos pontos em comum e pontos de discordância, que complementam o tema escolhido.

Os questionamentos basearam-se nos seguintes enfoques:

- Você conhece o Acordo Internacional da Previdência Social entre Brasil-Itália?

- No caso de você ter conhecimento da existência deste Acordo, através de que meio obteve esta informação? 
- No caso de você não ter conhecimento da existência deste Acordo, quem você acredita que deveria ter a competência de divulgá-lo?

- Você gostaria de ter maior conhecimento do Acordo citado e de sua área de abrangência?

- Caso você tenha interesse na obtenção de maior conhecimento do Acordo, através de que meio você irá buscar estas informações?

- Qual a sua opinião a respeito de um Acordo Internacional que beneficie reciprocamente imigrantes de um país quando residentes em outro país?

Além dos dados de identificação, que por questões éticas não são divulgados, formulou-se questões relativas à profissão, idade, escolaridade, tempo de residência e sobre o direito à saúde no país de destino, caso precisasse. Dos dez brasileiros que residem(iram) na Itália e responderam aos questionamentos, $60 \%$ (6/10) tinham idade entre 20 e 35 anos, $20 \%$ (2/ 10) de 51 a 65 anos, 10\% (1/10) acima de 66 anos e 10\% (1/10) entre 36 e 50 anos. O que foi constatado quanto ao nível de escolaridade dos questionados é que $70 \%$ (7/10) possuíam formação de pós-graduação em mestrado e doutorado, e os com nível superior somavam $20 \%(2 / 10)$ e os $10 \%(1 / 10)$ restantes de formação de nível médio. Quanto às profissões, 70\% (7/10) eram da iniciativa privada, $20 \%(2 / 10)$ aposentados e $10 \%(1 / 10)$ de atividades religiosas. O tempo de residência na Itália consistia em $40 \%(4 / 10)$ entre seis meses e um ano, de três anos a dez anos totalizou outros $40 \%(4 / 10)$ e mais de dez anos alcançou 20\% (2/10). Quanto ao Acordo entre os países, questionou-se o conhecimento de sua existência, ao que $60 \%(6 / 10)$ referiram que o conhecem, restando aos demais $40 \%$ (4/10) a afirmativa que desconheciam a existência do acordo. Os meios pelos quais obtiveram informações do Acordo foram as seguintes fontes: Patronato Italiano, site do INSS, Consulado Italiano no Brasil, Ministério da Saúde e indo pessoalmente ao INSS. Os 40\% (4/10) que não conheciam o Acordo responderam que quem deveria divulgá-lo eram os Consulados italianos no Brasil, os Consulados brasileiros na Itália e profissionais da área de turismo. Também deveriam divulgar o Ministério das Relações Exteriores e o Ministério da Saúde. Quando se pergunta, caso você necessitasse de atendimento na Itália a quem recorreria? $70 \%$ (7/10) responderam que procurariam o serviço público italiano e $30 \%(3 / 10)$ recorreriam à profissional particular.

Dos questionados, $70 \%$ (7/10) gostariam de ter maior conhecimento do Acordo, mesmo não precisando utilizá-lo, 20\% (2/10) não gostariam e $10 \%(1 / 10)$ necessitavam de maior conhecimento, pois pretendiam utilizá-lo. Em outra seara, 90\% (9/10) afirmaram a necessidade e importância deste acordo. Quanto à divulgação 80\% (8/10) consideraram a mesma ruim e $20 \%$ (2/10), razoável. A opinião quanto à utilização, mesmo daqueles que não precisaram, mas que acompanharam outros brasileiros, foi da dificuldade na hora de validar e usufruir deste Acordo. 
Quanto aos italianos que residiram ou residem no Brasil, $60 \%(6 / 10)$ tinham idade de 36 a 50 anos e 40\% (4/10) acima de 65 anos. A escolaridade consistia de $40 \%$ (4/10) nível superior, 50\% (5/10) a nível de pós-graduação e $10 \%(1 / 10)$ de nível médio. Quanto às profissões, $40 \%$ eram aposentados e $60 \%$ labutavam na iniciativa privada. O tempo de residência no Brasil perfazia 90\% (9/10) de 5 a 10 anos, e 10\% (1/10) com mais de 10 anos de permanência.

Quanto ao Acordo entre os países, questionou-se o conhecimento, e $30 \%(3 / 10)$ conheciam o Acordo, 40\% (4/10) não tinham conhecimento e $30 \%(3 / 10)$ conheciam parcialmente. Os meios em que obtiveram informações do Acordo foram sites do INSS e o Consulado Italiano. Os 40\% (4/10) que não conheciam o Acordo responderam que quem deveria divulgá-lo eram os Consulados italianos no Brasil, o Ministério da Saúde e profissionais de comunicação. Quando da pergunta, caso você necessitasse de atendimento no Brasil a quem recorreria? $60 \%(6 / 10)$ responderam que procurariam clínicas e hospitais privados e $40 \%$ (4/10) o setor público. Dos questionados, $80 \%(8 / 10)$ gostariam de ter maior conhecimento do Acordo, 20\% (2/10) não viram necessidade do Acordo. Quanto à divulgação: 70\% (7/10) consideraram ruim e $30 \%(3 / 10)$, razoável.

A partir destes questionamentos, em princípio, considera-se que um tratado consiste numa negociação, e que, a partir do momento do comprometimento do tratado ou acordo, esse tem condições de vigência imediata. Conforme publicação do Ministério da Previdência e Assistência Social, de 2001, um tratado é aprovado pelo Senado Federal e a ratificação é realizada pelo Presidente da República passando a vigorar no Brasil, onde, compete à Assessoria de Assuntos Internacionais do Ministério da Previdência e Assistência Social, a coordenação dos documentos técnicos dos acordos internacionais, bem como o acompanhamento e a avaliação de sua operacionalidade. O Instituto Nacional de Seguro Social, INSS, é o órgão gestor, ou seja, é a instituição competente para conceder e operacionalizar as prestações previstas nos acordos, por intermédios de órgãos regionais, que atuam como organismos de ligação. São beneficiários dos acordos internacionais, os segurados e seus dependentes sujeitos ao Regime de Previdência Social dos Países Acordantes. Os Acordos de Previdência Social aplicam-se aos benefícios do Regime de Previdência Social brasileiro.

Para a obtenção de um benefício no âmbito do acordo internacional, o segurado faz um requerimento de benefício, que deve ser protocolizado na entidade gestora do país de residência do interessado. No Brasil, os requerimentos são formalizados nas unidades/agências do INSS em cada Unidade da Federação e encaminhados ao organismo de ligação correspondente, conforme a residência do beneficiário. Os organismos de ligação são setores competentes do INSS para fazer a ligação com o setor competente do órgão previdenciário estrangeiro. No Brasil, estes órgãos situam-se no Distrito Federal, Rio de Janeiro, São Paulo, Rio Grande do Sul, 
Santa Catarina e Paraná. Os acordos internacionais preveem o instituto do deslocamento temporário que permite ao trabalhador continuar vinculado à Previdência Social do país de origem quando deslocado para outro país, por período preestabelecido no referido acordo. Ao empregado é fornecido um Certificado de Deslocamento Temporário visando à isenção de contribuição deste segurado no país acordante. Os Acordos Internacionais de Previdência preveem a Prestação de Assistência Médica no Exterior aos brasileiros e estrangeiros que se deslocam, administrada pelas Coordenadorias Regionais de Assistência à Saúde do Ministério da Saúde.

O trâmite do processo é bastante burocrático e tem-se conhecimento da demora na agilização deste processo. Após a protocolização do requerimento na Unidade da Previdência Social, este é encaminhado à Gerência Executiva a qual pertence. As gerências, após a conferência da documentação encaminham ao organismo de ligação naquele Estado. Aqueles que não residem nos Estados que possuem o órgão de ligação, encaminham seus processos ao de Brasília. A partir daí, este envia ofício ao organismo de ligação do país acordante (2 vias). A documentação é examinada e retorna a Brasília, que encaminha novamente à Agência/Unidade para chamamento do interessado.

As entidades de "Patronato" são as que operam no Brasil com a função de prestar assistência administrativa e jurídica no setor da Previdência Social às comunidades de descendentes de italianos e italianos residentes no Brasil, em razão dos acordos internacionais entre Itália e Brasil. Ao realizar a pesquisa, os sites de Consulados Brasileiros e Italianos foram consultados a procura de informações a respeito deste Acordo. O que se obteve, inclusive com posicionamento pessoal de representante diplomático no Canadá que está ultimando acordo de iguais características com o Brasil, é que as repartições consulares brasileiras não funcionam como intermediárias entre as instituições previdenciárias italianas (INPS) ou brasileiras (INSS), ou, por extensão, de outros países. Consequentemente, estas repartições não estão habilitadas a prestar informações sobre aposentadoria ou recebimento de pagamento previdenciário e não encaminham processos sobre essas matérias. Assim sendo, qualquer esclarecimento, bem como o requerimento de serviços referentes às questões previdenciárias devem ser solicitados diretamente pelo interessado aos respectivos escritórios das Instituições previdenciárias. Os únicos serviços prestados por estas repartições consulares brasileiras são a regularização do CPF, emissão de procuração para poderes junto ao INSS do Brasil e Atestado de Vida, para aqueles que recebem aposentadoria. Qualquer documento emitido por autoridade estrangeira, como é o caso do INPS italiano, para ter valor legal no Brasil, deve antes de seu envio, ser devidamente legalizado pela repartição consular brasileira com jurisdição sobre o local onde se encontra a autoridade estrangeira que emitiu tal documento e, posteriormente, ser traduzido por tradutor juramentado no Brasil. O envio ao Brasil desses documentos é de responsabilidade do interessado. 
Por meio desta análise, e dos questionamentos feitos a brasileiros e italianos quanto ao Acordo existente entre os países, observou-se que há necessidade de mais informações do Ministério da Previdência Social, das Relações Exteriores e dos próprios Consulados. Com a interdependência de um mundo globalizado e a saúde como um elemento essencial, é necessária de uma dinâmica entre a diplomacia para reorientar as políticas externas relativas à saúde de maneira a contribuir para a proteção da saúde global e os aspectos previdenciários.

\section{CONSIDERAÇÕES FINAIS}

O estudo, em seu conjunto, sublinha o crescente papel internacional que a Previdência Social desempenha, bem como a crescente dimensão de seus atributos e competências em nível da propagação das relações exteriores, na formulação e consolidação da garantia da qualidade de vida. A Previdência é um sistema de solidariedade nacional, administrada por um Estado e, no momento, em que ocorrem migrações populacionais, encontramse limites à capacidade de estender a proteção social para além das fronteiras nacionais. Em decorrência desses movimentos migratórios e da intensidade de seu fluxo impõem-se os acordos internacionais de Previdência Social que permitem coordenar as diferentes legislações dos países envolvidos, de maneira a estabelecer regras de reconhecimento recíproco.

Ora, não há qualquer país com legislação previdenciária exatamente igual ao de outro país, logo, tais arestas devem ser objeto de aplainamentos que possibilitem minorar suas consequências danosas, em prol de um fornecimento mais justo e equânime. Em função destas diferenças, os acordos internacionais bilaterais buscam, mesmo sem alterar a legislação dos dois países que permanece em vigor, equacionar devidamente os direitos obtidos a par de estendê-los, com as devidas reservas, aos beneficiários da outra pátria. Não se encontra plenamente a reciprocidade, pois nem todos os aspectos da legislação relevante podem estar contemplados em um acordo internacional, com díspares legislações regulamentadoras, mas, na medida em que o bem maior é a vida humana, promoções de benefícios além fronteiras assumem papel de reconhecimento social.

Ainda que os dois países adotem estratégias muito semelhantes em suas políticas de proteção social no que tange à concretização da fase assistencial do direito à saúde, tal fato somente se consolidou nos meados do último século, tendo em conta que, até então, na maior parte do processo histórico, essas estratégias encontravam-se temporalmente distanciadas. Mas, ainda que demorada, dita aproximação foi contundente para o estabelecimento de metas mútuas de interesse previdenciário entre o Brasil e a Itália, influenciando de maneira positiva os propósitos conjuntos de interesse individual e recíproco e alcançando patamares diferenciados de relacionamento fraternal. 
Por meio de acordos internacionais, a Previdência Social Brasileira concedeu, em 2004, 218 benefícios no valor de $\mathrm{R} \$ 142,7$ mil, o que representa uma diminuição de, respectivamente, 50,9\% e 42,5\% em relação ao ano anterior. As pensões por morte e as aposentadorias por tempo de contribuição foram as espécies cujas participações foram mais relevantes, atingindo, respectivamente $57,2 \%$ e $24,8 \%$ do valor total concedido. Os países com maior participação no valor total foram Portugal com 66,8\% e Espanha com $12,6 \%$, cabendo à Itália o inexpressivo percentual de $0,9 \%$, conforme o site da Previdência Social em seu Anuário Estatístico com fonte na DATAPREV. Tais dados são relevantes uma vez que demonstram a inversa proporcionalidade entre um fluxo migratório crescente e a decrescente concessão de benefícios naquele período.

Há um crescente reconhecimento, entre os países, da importância de que os direitos humanos dos migrantes e suas famílias sejam preservados, especialmente em um período marcado pela formação de grandes blocos de países e o aumento significativo de fluxos migratórios. A importância destes acordos de Previdência Social é que somente com eles se torna possível o reconhecimento do tempo de contribuição feito no exterior para outro regime. O mesmo vale para o estrangeiro de um desses países quando em relação com o Brasil. Nos países que não possuem acordo, nada disto se viabiliza.

Diante do inexorável reconhecimento internacional da importância de legislações que garantam, em nível interno a cada país, a assistência previdenciária de sua população, a par da bilateralidade e multilateralidade quando pretendida por dois ou mais Estados simultaneamente, imprime-se que os potenciais beneficiários sejam cientes de suas prerrogativas de alcance dos benefícios a que fazem jus. Inexplicável que haja tamanho desconhecimento de direitos reconhecidos, primordialmente, como demonstrou a pesquisa realizada, sobre público-alvo que tenha formação e experiência profissional em nível bem superior à média dos indivíduos em geral. Se, entre uma amostragem de entrevistados que se mostrou predominantemente diferenciada para uma cultura privilegiada, houve a ocorrência expressiva de desconhecimento da existência ou termos do acordo mantido entre o Brasil e a Itália, o que dizer de toda aquela maciça parcela da população cujo acesso às informações é precário? Ainda que grande parte da população de ambos os países esteja enraizada, não tendo pretensão nem condições de buscar perspectivas de qualquer ordem no outro Estado, como justificar a falta de conhecimento de acordos desta natureza?

O círculo vicioso que explicaria tal carência pode ser traçado a partir da relativa falta de informação, que gera falta de conhecimento, que gera falta de informação - infindável, se não truncado, o processo pela inserção de dispositivos e providências que alterem esta prejudicial cadeia de omissões.

Um dos procedimentos passíveis de resolução reside no aparelhamento das Representações Diplomáticas de ambos os países, com treinamento 
específico de pessoal de contato ao público. Mister se faz que, a despeito das referidas Representações Diplomáticas afirmarem sua disfunção relativamente a tais competências, tais Consulados e Embaixadas são os mais concentrados organismos de um país presentes em outro, com representatividade política reconhecida, facilmente adaptáveis a uma representatividade social também reconhecível.

Outra forma de esclarecer a garantia de tais direitos é por meio de Conferências Internacionais, para permitir a troca de informações sobre a seguridade social, possibilitando, assim, o intercâmbio de conhecimento e práticas bem-sucedidas entre os segurados e a Previdência Social. Interessante seria a criação de um modelo de controle dos documentos enviados e recebidos por um órgão centralizador, sem burocracias, sem elevação de custos, e com agilidade para a obtenção dos benefícios perante aos acordos internacionais. Os dados poderiam ser repassados via on-line, sem prejuízo da segurança de identificação, com implementação de formulários únicos e específicos para a permissão de consultas.

É necessário repensar as relações internacionais nos acordos da Previdência Social, com cooperações entre instituições públicas capazes de dialogar e cumprir os acordos, na obtenção das garantias pactuadas, da divulgação para um bem-estar dos imigrantes das nações envolvidas. Além do mais, urge o desenvolvimento de uma assessoria na área de cooperação para brasileiros no exterior e estrangeiros no Brasil, ampliando as informações em sites, com levantamentos de dados tempestivos de instituições de saúde e ONGs, bem como qualificando a assistência e o direito à saúde. O desafio está na troca de informações entre as previdências dos países, premente a criação de um elo entre os organismos dos países que devam repassar estas informações; e destes países com sua população, esteja esta população em qualquer território, quando o segurado tenha o conhecimento de seus direitos e a necessária assistência.

Não se tem informação do alcance do interesse dos órgãos governamentais dos países parceiros na extensa divulgação dos dados acordados. Ainda que política, diplomática e socialmente defendidos os direitos dos migrantes na contextualização dos países de destino, poucas informações são disponibilizadas em caráter geral. É possível que, à medida do acréscimo de novos acordos, novos interesses sejam despertados para a efetiva e eficaz validação dos já existentes.

\section{REFERÊNCIAS BIBLIOGRÁFICAS}

BASSANEZI, M. S. B.; BÓGUS, L. M. M. Brasileiros soggiornanti na Itália: um perfil sociodemográfico. In: I SIMPÓSIO INTERNACIONAL SOBRE EMIGRAÇÃO BRASILEIRA, 1. 22-24 out. 1997, Lisboa. 
BERLINGUER, G. Bioética cotidiana. Brasília, DF: Ed. da UnB, 2004. ; TEIXEIRA, S. F.; CAMPOS, G. W. S. Reforma sanitária Itália e Brasil. São Paulo: Hucitec, 1988.

BÓGUS, L. M. M. Globalização e migração internacional: o que há de novo nesses processos? In: DOWBOR, L.; IANNI, O.; RESENDE, P. E. A. (Orgs.). Desafios da globalização. Rio de Janeiro: Vozes, 1997.

; BASSANEZI, M. S. B. Do Brasil para a Europa: imigrantes brasileiros na Península Itálica neste final de século. In: $O$ fenômeno migratório no limiar do 3o milênio. Rio de Janeiro: Vozes, 1998.

BONIFAZI, C. Size and characteristics of foreign immigration in Italy. Labour, 1994.

BRASIL. Ministério da Previdência e Assistência Social. Acordos Internacionais de Previdência Social/Brasil. Ministério da Previdência e Assistência Social. Brasília: MPAS, 2001. 180 p.

CAVICCHI, I. La sanitá. Bari: Dédalo, 2005.

COHN, A.; ELIAS, P. E. (Orgs.). Saúde no Brasil: políticas e organização de serviços. São Paulo: Cortez; Cedec, 1996.

DA ROS, M. A. Uma visão da reforma curricular a partir do movimento sanitário. In: PEREIRA, M. J. L.; COELHO, E. B. S.; DA ROS, M. A. (Orgs.). Da proposta à ação: currículo integrado do Curso de Medicina da UFSC. Florianópolis: Ed. UFSC, 2005.

DALLARI, Dalmo de Abreu. Elementos de teoria geral do Estado. 16. ed. São Paulo: Saraiva, 1991.

DALLARI, Sueli Gandolfi. O direito à saúde. Revista de Saúde Pública. São Paulo, n. 22, p. 57-63, 1988.

DECLARAÇÃO DE ALMA ATA - URSS (1978). Disponível em: <http:// www.opas.org.br/coletiva/carta.cfm?idcarta>. Acesso em: fev. 2010.

DECLARAÇÃO UNIVERSAL DOS DIREITOS DO HOMEM (1948). Disponível em: <http://www.ghente.org/doc_juridicos/decdirhumanos.htm>. Acesso em: fev. 2010.

DIAS, Hélio Pereira. A responsabilidade pela saúde: aspectos jurídicos. Rio de Janeiro: Fiocruz, 1995.

DIAS, Sônia; GONÇALVES, Aldina. Migração e saúde. Revista Imigração. número temático Imigração e saúde, Lisboa, n. 1, p. 15-26, set. 2007. Disponível em: $<w w w$.oi.acidi.gov.pt/docs/Revista_1/migracoes1_art1.pdf>. Acesso em: 09 mar. 2010.

ESCOREL, S. Reviravolta na saúde: origem e articulação do movimento sanitário. Rio de Janeiro: Fiocruz, 1998.

GENTIL, D. L. Breve relato histórico do sistema de proteção social. In: A política fiscal e a falsa crise da seguridade social brasileira: análise financeira do período 1990-2005. 2006. Tese (Doutorado em Economia) - Instituto de Economia da UFRR, Rio de Janeiro, 2006. 
LIMA, N. T.; FONSECA, C. M.; HOCHMAN, G. A saúde na construção do estado Nacional no Brasil: reforma sanitária em perspectiva histórica. In: LIMA, N. T. et al. (Orgs.). Saúde e democracia: história e perspectivas do SUS. Rio de Janeiro: Fiocruz, 2005.

MENDES, E. V. Uma agenda para a saúde. 2. ed. São Paulo: Hucitec, 1999. MINISTÉRIO DA PREVIDÊNCIA SOCIAL. Disponível em: <http:// www.previdenciasocial.gov.br>. Acesso em: 23 fev. 2010.

MINISTÉRIO DA SAÚDE. Disponível em: <http://portal.saude.gov.br/portal/ saude/Gestor/area.cfm?id_area=169>. Acesso em: 13 jun. 2010.

MINISTÉRIO DAS RELAÇÕES EXTERIORES. Disponível em: <http:// www.mre.gov.br>. Acesso em: 23 fev. 2010.

REPUBBLICA ITALIANA. La Costituzione della Repubblica Italiana. Roma, 1947. Disponível em: <http://www.quirinale.it/costituzione/costituzione.htm>. Acesso em: 25 fev. 2010.

Decreto Legislativo n. 229, del 19 giugno 1999. Norme per la razionalizzazione del Servizio Sanitario Nazionale, a norma dell'articolo 1 della legge 30 novembre 1998, n. 419. Gazzetta Ufficiale, Roma, 16 luglio 1999. Disponível em: <http://www.parlamento.it/leggi/deleghe/99229dl.htm>. Acesso em: 25 fev. 2010.

Ministero della Salute. Pianno Sanitário Nazionale 2006-2008. Roma, 2006. Disponível em: <http://db.formez.it/FontiNor.nst/edc98cc539249bcac1256 da500491c81/3360B412 FFBD72F7C125723D003B6C97/\$file/PSN\%202 006-08\%20TESTO.pdf:>. Acesso em: 25 fev. 2010.

ROCHA, Julio César de Sá da. Direito da saúde: direito sanitário na perspectiva dos interesses difusos e coletivos. São Paulo: LTr, 1999.

SCHWARTZ, Germano André Doederlein. Direito à saúde: efetivação em uma perspectiva sistêmica. Porto Alegre: 2001.

SCLIAR, Moacir. Do mágico ao social: a trajetória da saúde pública. Porto Alegre: L \& PM, 1987.

STURZA, Janaína Machado. O direito à saúde na sociedade contemporânea: a figura jurídica do dano biológico na Itália e a proteção à saúde no Brasil. Disponível em: <www.unisc.br/cursos/pos_graduacao/.../janaina_machado_ sturza.pdf>. Acesso em: 10 mar. 2010.

TEIXEIRA, S. F. (Org.). Reforma sanitária. São Paulo: Cortez, 1989.

VENTURA, Deisy; SEITENFUS, Ricardo. Direito internacional público. 4. ed. Porto Alegre: Livraria do Advogado, 2006.

VERDI, M. I. M. Da Haussmannização às cidades saudáveis: rupturas e continuidades nas políticas de saúde e urbanização na sociedade brasileira do início e do final do Século XX. 2002. Tese (Doutorado em Enfermagem) Universidade de Santa Catarina, Florianópolis, 2002. 